\title{
Outcome of laparoscopic paraesophageal hernia repair in octogenarians: a registry-based, propensity score-matched comparison of 360 patients
}

\author{
Ralph F. Staerkle ${ }^{1} \cdot$ Ilan Rosenblum ${ }^{1} \cdot$ Ferdinand Köckerling $^{2} \cdot$ Daniela Adolf $^{3} \cdot$ Reinhard Bittner $^{4} \cdot$ Philipp Kirchhoff $^{1}$. \\ Frank S. Lehmann ${ }^{5}$ · Henry Hoffmann ${ }^{1}$. Philippe M. Glauser ${ }^{1} \mathbb{B}$
}

Received: 13 July 2018 / Accepted: 3 December 2018 / Published online: 10 December 2018

(c) The Author(s) 2018

\begin{abstract}
Background Paraesophageal hernias (PEH) tend to occur in elderly patients and the assumed higher morbidity of PEH repair may dissuade clinicians from seeking a surgical solution. On the other hand, the mortality rate for emergency repairs shows a sevenfold increase compared to elective repairs. This analysis evaluates the complication rates after elective PEH repair in patients 80 years and older in comparison with younger patients.

Methods In total, 3209 patients with PEH were recorded in the Herniamed Registry between September 1, 2009 and January 5 , 2018. Using propensity score matching, 360 matched pairs were formed for comparative analysis of general, intraoperative, and postoperative complication rates in both groups.

Results Our analysis revealed a disadvantage in general complications $(6.7 \%$ vs. $14.2 \% ; p=0.002)$ for patients $\geq 80$ years old. No significant differences were found between the two groups for intraoperative ( $4.7 \%$ vs. $5.8 \%, p=0.627)$ and postoperative complications ( $2.2 \%$ vs. $2.8 \%, p=0.815)$ or for complication-related reoperations $(1.7 \%$ vs. $2.2 \%, p=0.791)$.

Conclusions Despite a higher risk of general complications, PEH repair in octogenarians is not in itself associated with increased rates of intraoperative and postoperative complications or associated reoperations. Therefore, PEH repair can be safely offered to elderly patients with symptomatic $\mathrm{PEH}$, if general medical risk factors are controlled.
\end{abstract}

Keywords Paraesophageal hernia repair $\cdot$ Complications $\cdot$ Elderly patients $\cdot$ Propensity score-based $\cdot$ Matched-pair analysis

Hiatal hernias are divided into types I-IV, of which approximately $5-15 \%$ are paraesophageal hernias (PEH) (types

Ralph F. Staerkle and Ilan Rosenblum have contributed equally to this work.

Henry Hoffmann, Philippe M. Glauser: Shared senior authorship.

Electronic supplementary material The online version of this article (https://doi.org/10.1007/s00464-018-06619-4) contains supplementary material, which is available to authorized users.

Philippe M. Glauser

philippe_glauser@yahoo.com

1 Department of General and Visceral Surgery, University Hospital Basel, Spitalstrasse 21, 4031 Basel, Switzerland

2 Department of Surgery and Center for Minimally Invasive Surgery, Academic Teaching Hospital of Charité Medical School, Vivantes Hospital, Neue Bergstrasse 6, 13585 Berlin, Germany
II-IV) [1]. PEH is defined as herniation of the stomach and/ or other viscera through a dilated hiatal aperture alongside the esophagus $[1,2]$. These hernias tend to be found more frequently in elderly women, although adults of any sex and age may be affected [3]. Dysphagia, vomiting, and regurgitation, often associated with retrosternal pain, are typical symptoms [3]. Pharmacological treatment is often unsatisfactory since PEH symptoms are mostly related to the mechanical effects of the hernia.

StatConsult GmbH, Halberstädter Straße 40 a, 39112 Magdeburg, Germany

4 Winghofer Medicum Hernia Center, Winghofer Straße 42, 72108 Rottenburg am Neckar, Germany

5 Division of Gastroenterology and Hepatology, University Hospital Basel, Petersgraben 4, 4031 Basel, Switzerland 
The annual incidence of acute symptoms in patients with PEH ranges between 0.7 and 7\% [4, 5]. Emergency repairs of PEH are associated with a sevenfold increase in mortality compared with elective repairs [6]. Several studies showed that elective laparoscopic PEH repair has a low morbidity resulting in significantly improved quality of life [3, 7-11]. Although elective PEH repair may be used increasingly in older patients [12], the assumed higher perioperative morbidity in elderly patients may dissuade clinicians from seeking a surgical solution.

However, data on perioperative outcomes of elective PEH repair in octogenarians or older patients are sparse. One study analyzing short-term outcomes associated with PEH repair in patients aged 80 years and older revealed higher rates of minor morbidity, but no significant differences in mortality or major morbidity rates compared to younger patients [11].

In this registry-based, matched-pair analysis, intraoperative, postoperative, and general complication rates after elective PEH repair in patients $\geq 80$ years were assessed and compared to younger patients.

\section{Methods}

The Herniamed Registry is a multicenter, internet-based hernia registry [13] with 644 participating hospitals and surgeons in private practice (Herniamed Study Group) in Germany, Austria, and Switzerland (status: January 5, 2018) who have shared data on their patients undergoing routine hernia surgery. All patients signed an informed consent form agreeing to participate. As part of the information provided to patients regarding participation in the Herniamed Quality Assurance Study and signing the informed consent declaration, all patients were informed that the treating hospital or medical practice should be informed about any problem occurring after the operation and that the patient should have a clinical examination if needed. All postoperative complications occurring up to 30 days after surgery are recorded.

The current analysis compares the prospective data gathered on PEH repairs in octogenarians ( $\geq 80$ years) and younger patients ( $<80$ years) between September 1, 2009 and January 5, 2018 using a matched-pair analysis. The main inclusion criteria were hiatal hernia operation, complete entry state, paraesophageal hernia (types II-IV), minimum age of 16 years, primary operation, and no emergency repair. In total, 3209 patients were enrolled (Fig. 1). Pairwise propensity score (PS) matching analysis was performed for these 3209 patients to obtain homogeneous comparison groups.

The data collected were age, body mass index (BMI), type of fundoplication, type of hiatal hernia, type of hiatal repair, American Society of Anesthesiologist (ASA) status, and gender.

The following risk factors were assessed as possible risk factors for an adverse outcome: chronic obstructive pulmonary disease (COPD), diabetes mellitus, aortic aneurysm, immunosuppression, steroids, smoking, coagulation disorder, or antiplatelet or anticoagulant therapy. All analyses were performed with the software SAS 9.4 (SAS Institute Inc., Cary, NC, USA) and intentionally calculated to a full significance level of 5\%, with the exception of post hoc analyses for single general complications. Here, adjustment for multiple testing was made using a Bonferroni correction (factor 16).

Analogous to previous registry-based analyses [14], intraoperative complications (bleeding, injury to esophagus, bowel, spleen, stomach, or liver), postoperative complications (esophageal perforation, gastric perforation, bleeding, infection, wound healing disorder, or ileus), overall complications, and complication-related reoperations were compared between age groups using, first of all, PS matching. Matched samples were analyzed with McNemar's test. Outcomes are given as the non-diagonal elements of the $2 \times 2$ frequency table, which represent differences in the matched samples, the corresponding $p$-values, and the odds ratio (OR) estimates for matched samples. PS matching was performed using greedy algorithm and a caliper of 0.1 standard deviations. The variables used for matching were sex (male/female), type of fundoplication, BMI $\left(\mathrm{kg} / \mathrm{m}^{2}\right)$, hernia type (II, III, IV), risk factors (COPD, diabetes, aortic aneurysm, immunosuppression, steroids, smoking, coagulation disorder, anticoagulants, antiplatelet therapy), and ASA classification (I, II, III, IV). The balance of the matched sample was checked using standardized differences (also given for the original sample) that should not exceed $10 \%(<0.1)$ after creating matched pairs. For pairwise comparison of matching parameters between age groups (for presenting the differences between the original samples), $\chi^{2}$ tests and $t$ tests (Satterthwaite) were performed for categorical and continuous variables, respectively. Furthermore, loess regression was performed to visualize the unadjusted relationship between age (years) and binary complication rates.

\section{Results}

Out of the 3209 patients with PEH repair, 381 (11.9\%) were aged $\geq 80$ years. The vast majority of the repairs were done laparoscopically in both groups, at $93.8 \%$ ( $<80$ years) and $91.4 \%$ ( $\geq 80$ years), respectively. 


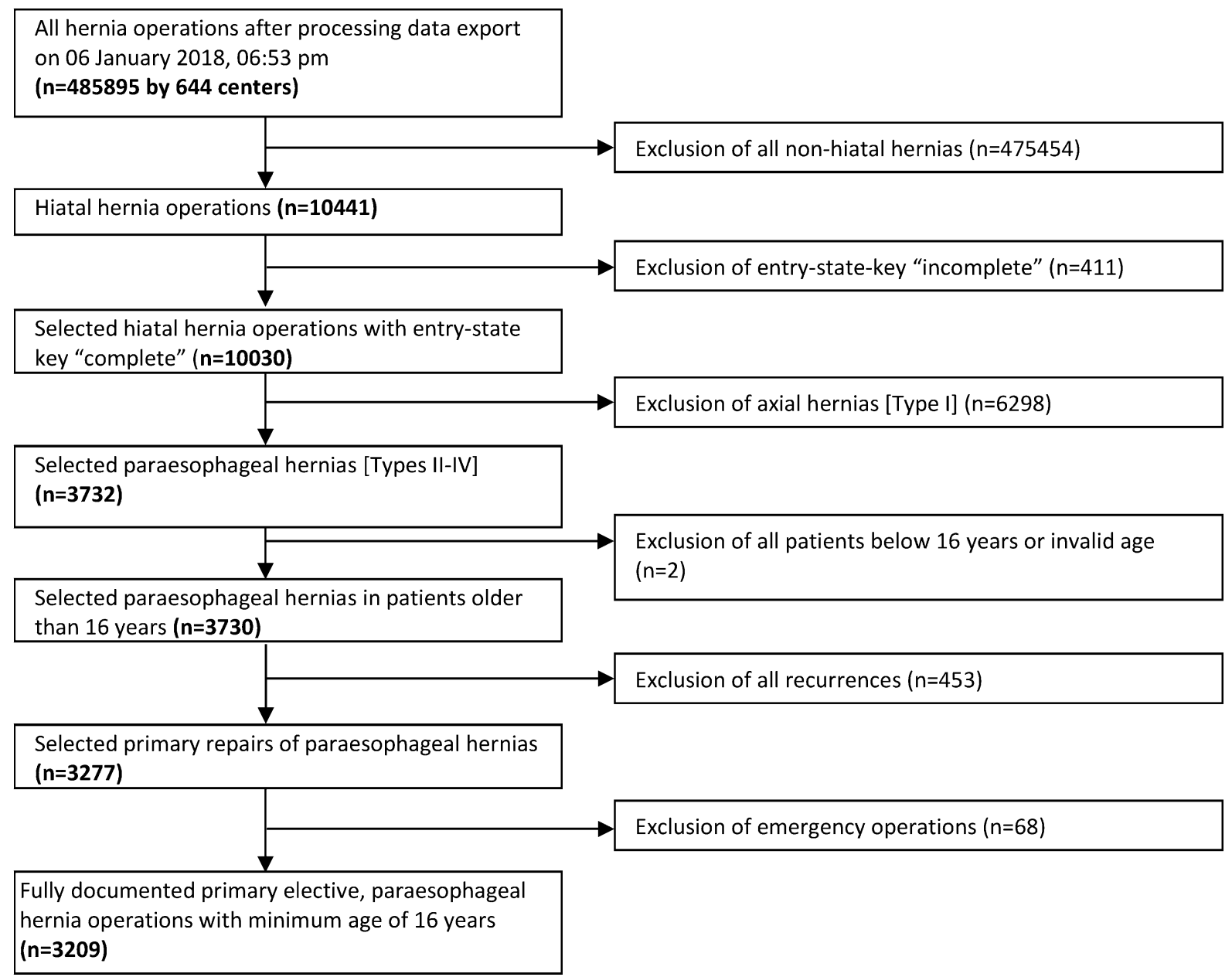

Fig. 1 Flowchart of patient inclusion

\section{Unadjusted analysis before matching}

When comparing the frequency distribution of the different matching variables, significant differences were found. The BMI in patients $\geq 80$ years old was significantly lower compared to the BMI of younger patients (mean $26.6 \pm 4.5$ vs. $29.0 \pm 5.0 ; p<0.001)$. Patients $\geq 80$ years had significantly fewer fundoplications, larger hernias, a higher ASA score, more risk factors, and were predominately female (Table 1).

\section{Standardized differences after propensity score matching}

Matching was successfully applied for 360 patients $\geq 80$ years $(94.5 \%)$. The group $<80$ years had a mean age of 68.2 years (SD 9.67), whereas the group $\geq 80$ years had a mean age of 83.6 years (SD 3.21) (Fig. 2).

Table 2 shows the distribution after matching and the standardized differences in the categorical matching variables before (original sample) and after matching (matched sample). All the matching variables show a difference of less than $10 \%$, providing a good balance of those variables in the matched sample. This also holds for BMI, which is $27.0 \pm 4.4$ and $26.8 \pm 4.5$ in patients $<80$ years and patients $\geq 80$ years after matching, respectively (standardized difference $=0.043$ ).

\section{Matched-pair analysis}

The matched-pair analysis revealed no systematic differences for intraoperative complications. There were $5.8 \%$ events only in the older group compared to $4.7 \%$ events only in younger patients (OR 1.235 [0.621; 2.494]; $p=0.627$ ). Postoperative complications occurred in $2.8 \%$ of the matched pairs in older patients only and in $2.2 \%$ in younger patients only (OR 1.250 [0.444; 3.645]; $p=0.815$ ). Patients $\geq 80$ years showed significantly more general complications compared to the matched patients of the younger group (OR 2.125 [1.284; 3.610]; $p=0.002$ ) (Fig. 3). On analyzing the frequency distribution of single general 
Table 1 Unadjusted analysis for the matching variables between the two age groups

\begin{tabular}{|c|c|c|c|c|c|}
\hline & \multicolumn{4}{|l|}{ Age } & \multirow[t]{3}{*}{$p$} \\
\hline & \multicolumn{2}{|c|}{$<80$ Years } & \multicolumn{2}{|c|}{$\geq 80$ Years } & \\
\hline & $n$ & $\%$ & $n$ & $\%$ & \\
\hline \multicolumn{6}{|l|}{ Fundoplication } \\
\hline Fundophrenicopexy & 517 & 18.28 & 113 & 29.66 & \multirow[t]{4}{*}{$<0.001$} \\
\hline Nissen fundoplication & 973 & 34.41 & 110 & 28.87 & \\
\hline Toupet fundoplication & 1044 & 36.92 & 116 & 30.45 & \\
\hline Other & 294 & 10.40 & 42 & 11.02 & \\
\hline \multicolumn{6}{|l|}{ Access } \\
\hline Laparoscopy & 2653 & 93.81 & 348 & 91.34 & \multirow[t]{2}{*}{0.075} \\
\hline Open & 175 & 6.19 & 33 & 8.66 & \\
\hline \multicolumn{6}{|l|}{ Type of hernia } \\
\hline Mixed & 726 & 25.67 & 55 & 14.44 & \multirow[t]{3}{*}{$<0.001$} \\
\hline Paraesophageal & 845 & 29.88 & 74 & 19.42 & \\
\hline Up-side-down stomach & 1257 & 44.45 & 252 & 66.14 & \\
\hline \multicolumn{6}{|l|}{ Hiatal repair } \\
\hline Other & 29 & 1.03 & 5 & 1.31 & \multirow[t]{4}{*}{0.138} \\
\hline Suture only & 1793 & 63.40 & 220 & 57.74 & \\
\hline Suture and mesh & 967 & 34.19 & 152 & 39.90 & \\
\hline Mesh & 39 & 1.38 & 4 & 1.05 & \\
\hline \multicolumn{6}{|l|}{ ASA } \\
\hline I & 291 & 10.29 & 8 & 2.10 & \multirow[t]{3}{*}{$<0.001$} \\
\hline II & 1654 & 58.49 & 120 & 31.50 & \\
\hline III/IV & 883 & 31.22 & 253 & 66.40 & \\
\hline \multicolumn{6}{|l|}{ Sex } \\
\hline Male & 947 & 33.49 & 86 & 22.57 & \multirow[t]{2}{*}{$<0.001$} \\
\hline Female & 1881 & 66.51 & 295 & 77.43 & \\
\hline \multicolumn{6}{|l|}{ Risk factors } \\
\hline \multicolumn{6}{|l|}{ Overall } \\
\hline Yes & 904 & 31.97 & 166 & 43.57 & \multirow[t]{2}{*}{$<0.001$} \\
\hline No & 1924 & 68.03 & 215 & 56.43 & \\
\hline \multicolumn{6}{|l|}{ COPD } \\
\hline Yes & 384 & 13.58 & 81 & 21.26 & \multirow[t]{2}{*}{$<0.001$} \\
\hline No & 2444 & 86.42 & 300 & 78.74 & \\
\hline \multicolumn{6}{|l|}{ Diabetes mellitus } \\
\hline Yes & 204 & 7.21 & 41 & 10.76 & 0.018 \\
\hline No & 2624 & 92.79 & 340 & 89.24 & \\
\hline Aortic aneurysm & & & & & \\
\hline Yes & 16 & 0.57 & 3 & 0.79 & 0.486 \\
\hline No & 2812 & 99.43 & 378 & 99.21 & \\
\hline Immunosuppression & & & & & \\
\hline Yes & 33 & 1.17 & 4 & 1.05 & 1.000 \\
\hline No & 2795 & 98.83 & 377 & 98.95 & \\
\hline Steroids & & & & & \\
\hline Yes & 62 & 2.19 & 15 & 3.94 & 0.048 \\
\hline No & 2766 & 97.81 & 366 & 96.06 & \\
\hline Smoking & & & & & \\
\hline Yes & 191 & 6.75 & 5 & 1.31 & $<0.001$ \\
\hline No & 2637 & 93.25 & 376 & 98.69 & \\
\hline
\end{tabular}

Table 1 (continued)

\begin{tabular}{|c|c|c|c|c|c|}
\hline & \multicolumn{4}{|l|}{ Age } & \multirow[t]{3}{*}{$p$} \\
\hline & \multicolumn{2}{|c|}{$<80$ Years } & \multicolumn{2}{|c|}{$\geq 80$ Years } & \\
\hline & $n$ & $\%$ & $n$ & $\%$ & \\
\hline \multicolumn{6}{|c|}{ Coagulation disorder } \\
\hline Yes & 48 & 1.70 & 15 & 3.94 & 0.009 \\
\hline No & 2780 & 98.30 & 366 & 96.06 & \\
\hline \multicolumn{6}{|c|}{ Antiplatelet therapy } \\
\hline Yes & 224 & 7.92 & 72 & 18.90 & $<0.001$ \\
\hline No & 2604 & 92.08 & 309 & 81.10 & \\
\hline \multicolumn{6}{|c|}{ Anticoagulation } \\
\hline Yes & 47 & 1.66 & 18 & 4.72 & $<0.001$ \\
\hline No & 2781 & 98.34 & 363 & 95.28 & \\
\hline
\end{tabular}

ASA American Society of Anesthesiologists status, COPD chronic obstructive pulmonary disease

complications, only pneumonia showed a significant difference between the two groups ( $p=0.041)$. There was no systematic difference in mortality (OR 2.000 [0.215; 35.199]; $p=1.000$ ) or in any of the other general complications between the two groups (Table 3). Finally, no systematic differences were found between age groups for complication-related reoperations $(1.7 \%$ vs. $2.2 \%, \mathrm{OR}=1.333[0.406$; 4.662], $p=0.791)$.

\section{Loess regression}

The results of unadjusted loess regression on all 3209 patients underline our results: Except for general complications, there were no reliable signs that more complications occurred in the older group (Fig. 4).

Furthermore, the results of unadjusted loess regression on only those patients of the matched samples revealed that the controls (patients $<80$ years) who were chosen for matching because of their comparable characteristics did not show higher complication rates in higher ages only (Fig. 5).

\section{Unadjusted analysis of 1-year follow-up data}

If we restrict the analysis population to those patients with one-year follow-up data, $n=1505$ patients $<80$ years old $(53.2 \%)$ and $n=160$ patients $\geq 80$ years old $(42.0 \%)$ remain. Since these follow-up rates are profoundly different, one can assume that patient inclusion is strongly biased, e.g., restricted to those patients $\geq 80$ years old who are relatively healthy. Nevertheless, we provide the recurrence rate, which is $4.8 \%$ in patients $<80$ years old $(n=72)$ and $1.9 \%$ in patients $\geq 80$ years old $(n=3)$, respectively $(p=0.092)$. 
Fig. 2 Age distribution within the age groups (after matching)

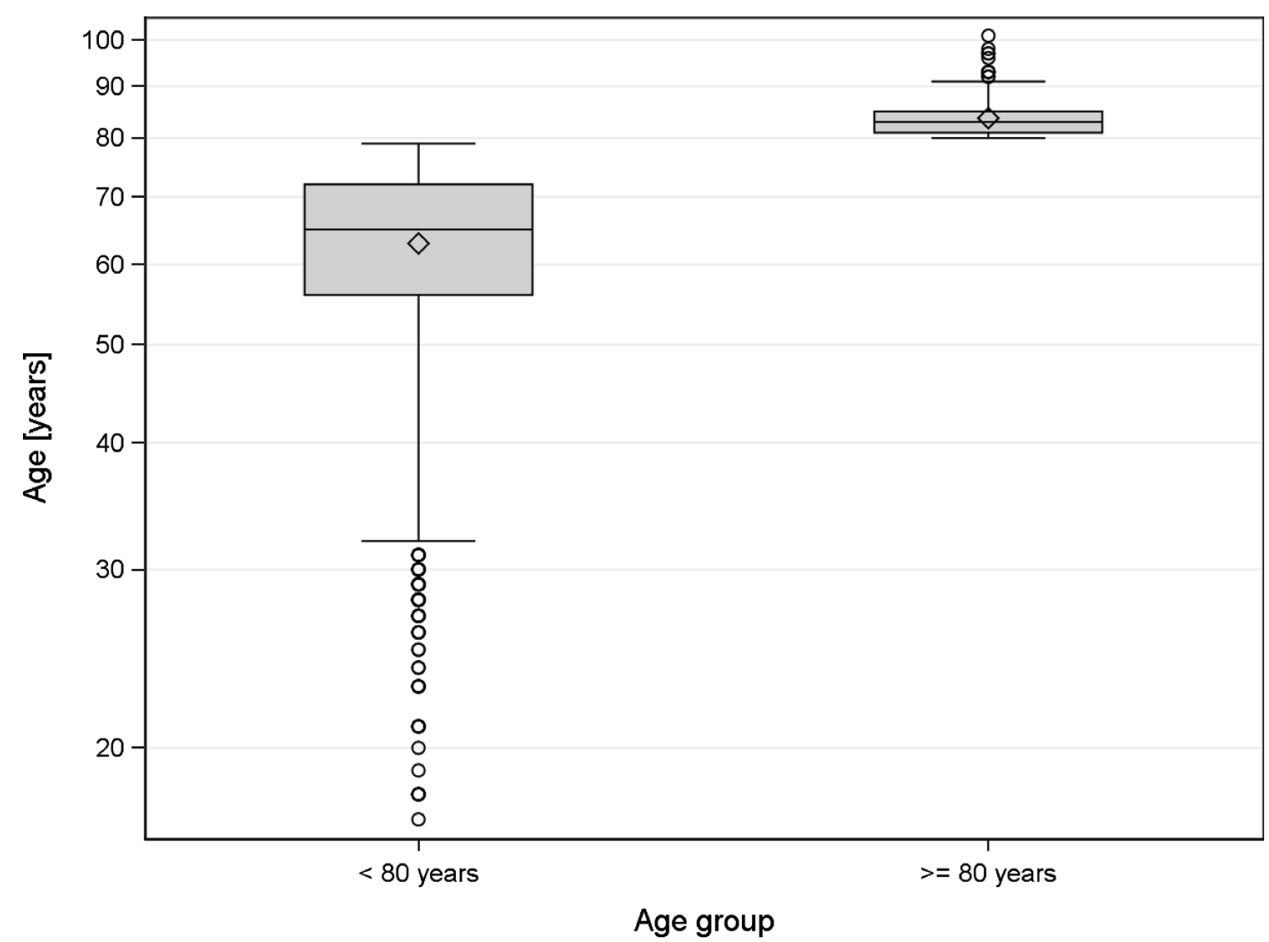

\begin{tabular}{|c|c|c|c|c|c|c|}
\hline & \multicolumn{2}{|c|}{$<80$ Years } & \multicolumn{2}{|c|}{$\geq 80$ Years } & \multicolumn{2}{|c|}{ Standardized difference } \\
\hline & $n$ & $\%$ & $n$ & $\%$ & Matched sample & Original sample \\
\hline Male & 83 & 23.06 & 83 & 23.06 & 0.000 & 0.245 \\
\hline ASA I & 6 & 1.67 & 8 & 2.22 & 0.040 & 0.345 \\
\hline ASA II & 115 & 31.94 & 119 & 33.06 & 0.024 & 0.564 \\
\hline ASA III-IV & 239 & 66.39 & 233 & 64.72 & 0.035 & 0.752 \\
\hline Other fundoplication & 38 & 10.56 & 38 & 10.56 & 0.000 & 0.020 \\
\hline Nissen fundoplication & 105 & 29.17 & 105 & 29.17 & 0.000 & 0.119 \\
\hline Toupet fundoplication & 110 & 30.56 & 110 & 30.56 & 0.000 & 0.137 \\
\hline Fundophrenicopexy & 107 & 29.72 & 107 & 29.72 & 0.000 & 0.269 \\
\hline Paraoesophageal & 82 & 22.78 & 72 & 20.00 & 0.068 & 0.244 \\
\hline Mixed & 46 & 12.78 & 54 & 15.00 & 0.064 & 0.283 \\
\hline Up-side-down stomach & 232 & 64.44 & 234 & 65.00 & 0.012 & 0.447 \\
\hline Risk factors & 168 & 46.67 & 154 & 42.78 & 0.078 & 0.241 \\
\hline Risk factor: COPD & 79 & 21.94 & 77 & 21.39 & 0.013 & 0.204 \\
\hline Risk factor: diabetes mellitus & 42 & 11.67 & 38 & 10.56 & 0.035 & 0.124 \\
\hline Risk factor: aortic aneurysm & 2 & 0.56 & 3 & 0.83 & 0.033 & 0.027 \\
\hline Risk factor: immunosuppression & 3 & 0.83 & 4 & 1.11 & 0.028 & 0.011 \\
\hline Risk factor: steroids & 13 & 3.61 & 14 & 3.89 & 0.015 & 0.101 \\
\hline Risk factor: smoking & 6 & 1.67 & 5 & 1.39 & 0.023 & 0.279 \\
\hline Risk factor: coagulation disorder & 8 & 2.22 & 12 & 3.06 & 0.052 & 0.136 \\
\hline Risk factor: antiplatelet therapy & 69 & 19.17 & 65 & 18.06 & 0.029 & 0.326 \\
\hline Risk factor: anticoagulation & 13 & 3.61 & 14 & 3.89 & 0.015 & 0.175 \\
\hline
\end{tabular}

ASA American Society of Anesthesiologists status, COPD chronic obstructive pulmonary disease 


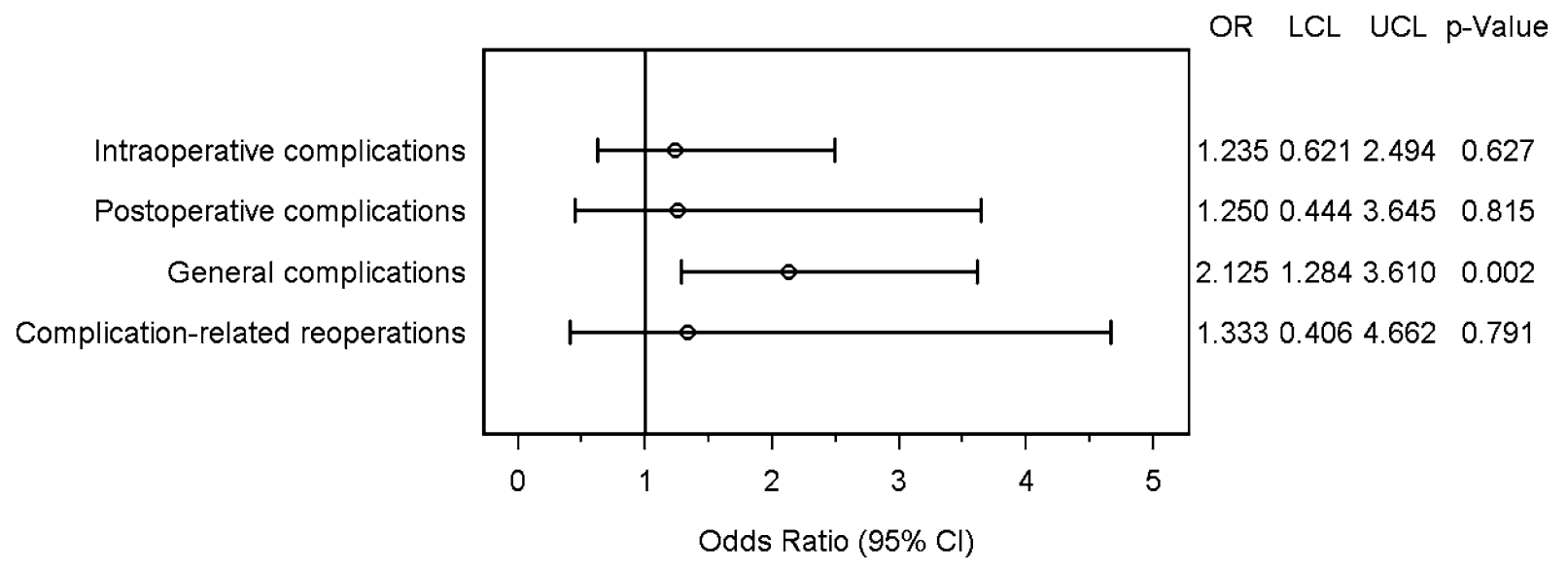

Fig. 3 Forest plot—adjusted odds ratios. $O R$ odds ratio, $L C L$ lower confidence limit, $U C L$ upper confidence limit

Table 3 General complications

\begin{tabular}{|c|c|c|c|c|c|c|}
\hline & \multicolumn{2}{|c|}{ Disadvantage } & \multirow[t]{2}{*}{$p$-value* } & \multicolumn{3}{|c|}{ OR* for matched samples } \\
\hline & $<80$ Years & $\geq 80$ Years & & OR & Lower limit & Upper limit \\
\hline Fever & 1.11 & 1.11 & 1.000 & 1.000 & 0.079 & 12.702 \\
\hline Urinary tract infection & 0.83 & 2.22 & 1.000 & 2.667 & 0.351 & 44.213 \\
\hline Diarrhea & 0.56 & 0.56 & 1.000 & 1.000 & 0.017 & 60.294 \\
\hline Gastritis & 0.00 & 0.00 & & & & \\
\hline Thrombosis & 0.00 & 0.00 & & & & \\
\hline Pulmonary embolism & 0.83 & 0.28 & 1.000 & 0.333 & 0.000 & 12.420 \\
\hline Pleural effusion & 2.50 & 4.44 & 1.000 & 1.778 & 0.497 & 7.451 \\
\hline Pneumonia & 0.83 & 4.72 & 0.041 & 5.667 & 1.028 & 84.669 \\
\hline COPD & 1.11 & 1.39 & 1.000 & 1.250 & 0.127 & 14.796 \\
\hline Heart failure & 0.83 & 2.78 & 1.000 & 3.333 & 0.495 & 53.213 \\
\hline Coronary heart disease & 0.56 & 1.11 & 1.000 & 2.000 & 0.118 & 95.634 \\
\hline Myocardial infarction & 0.28 & 0.56 & 1.000 & 2.000 & 0.024 & 1918.000 \\
\hline Renal failure & 0.83 & 1.11 & 1.000 & 1.333 & 0.094 & 26.159 \\
\hline Hypertensive crisis & 0.56 & 0.83 & 1.000 & 1.500 & 0.059 & 77.990 \\
\hline Death & 0.83 & 1.67 & 1.000 & 2.000 & 0.215 & 35.199 \\
\hline Other complications & 1.11 & 3.89 & 0.494 & 3.500 & 0.686 & 33.477 \\
\hline
\end{tabular}

Relative frequency of cases with disadvantage for the respective age group (non-diagonal elements of $2 \times 2$ contingency table)

$O R$ odds ratio, $C O P D$ chronic obstructive pulmonary disease

*Adjusted according to Bonferroni: factor 16

\section{Discussion}

This is the first propensity score-based, matched-pair analysis evaluating the complication rates of elective PEH in patients $\geq 80$ years old. Our study showed that elderly patients can undergo PEH with intraoperative and postoperative surgical complication rates comparable with those of younger patients. The only general complication that was significantly more frequent after PEH in patients $\geq 80$ years was pneumonia, highlighting the postoperative respiratory vulnerability of this patient population.

This study contributes to the ongoing and important discussion of balancing the perioperative risks and the supposed postoperative benefit of surgical procedures in elderly patients. Due to demographic trends in most countries, surgical patients increasingly present at an advanced age and with more comorbidities. It is accepted that advanced age in itself does not increase perioperative morbidity and mortality, and therefore there is no age limit for surgical interventions [15]. However, making therapeutic decisions for or 


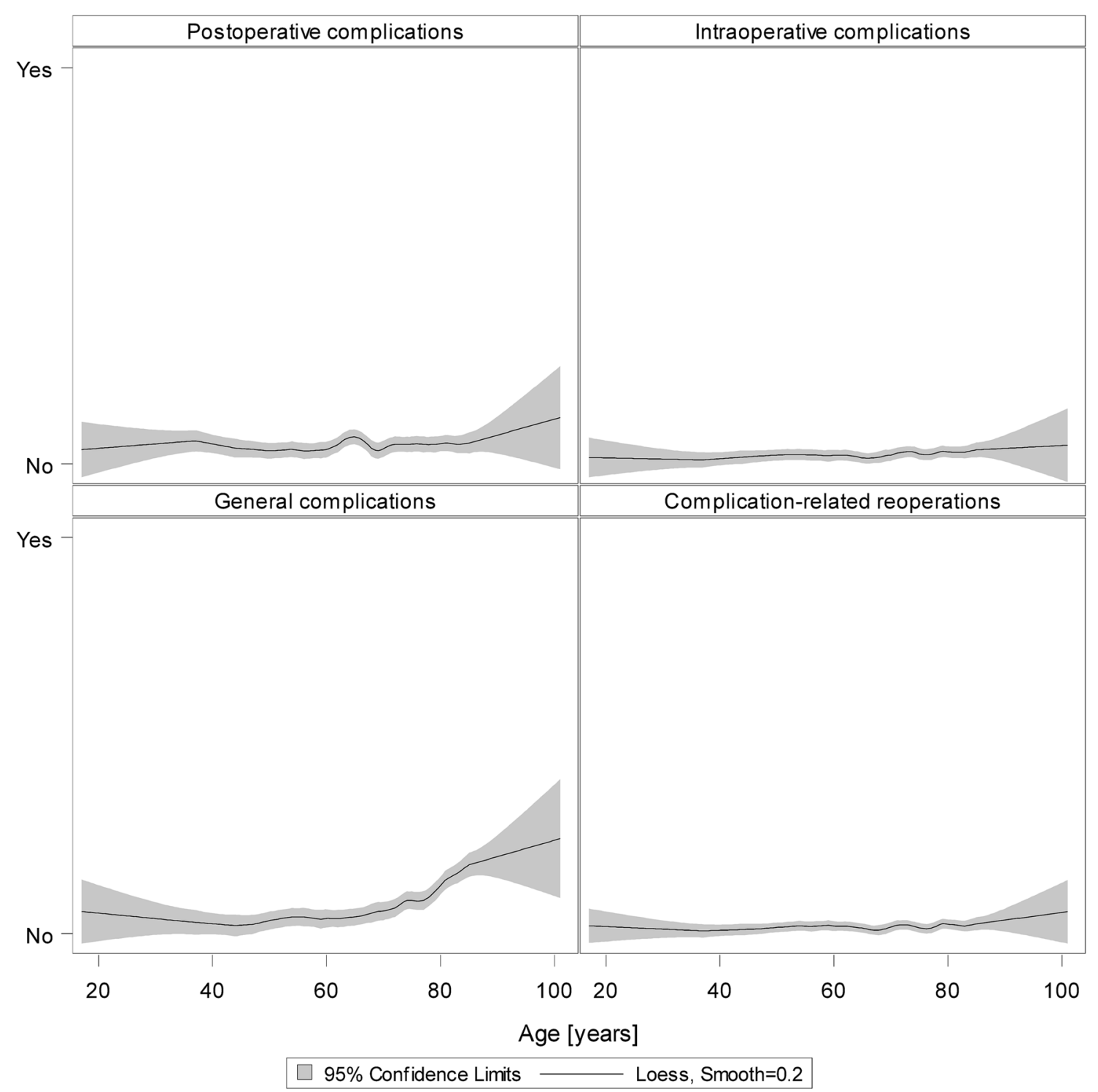

Fig. 4 Loess regression for postoperative, intraoperative, and general complications as well as complication-related reoperations for all patients $($ smooth $=0.2)$

against surgical treatment seems more challenging in older patients, since comorbidities may increase the surgical risk. Regarding PEH repair, one can argue that elective surgical treatment is the method of choice since symptoms may not be controlled with conservative treatment strategies and prevention of emergency situations with significantly higher morbidity and mortality seems appropriate [6]. There is a paucity of high-level evidence literature on elective PEH repair in elderly patients. A few studies defined elderly as $>70$ years $[3,8,9]$ or analyzed a very small group of elderly patients $[5,7,10,16]$, making comparison with our data difficult. Only one study evaluating elective PEH repair in 313 patients $\geq 80$ years revealed a significant increase in minor morbidity $(8.3 \%$ vs. $3.5 \%, p<0.001)$, and a trend towards slightly higher mortality ( $1 \%$ vs. $0.4 \%, p=0.16$ ) and major morbidity (5.8\% vs. $3.7 \%, p=0.083$ ) for patients $\geq 80$ years [11]. The authors concluded that PEH repair can be performed with minimal morbidity and mortality in elderly patients. However, the main limitation of this study and most other observational studies is its confounding bias, especially when comparing two very different and unequal patient populations. Our propensity score, registry-based study revealed comparable rates for perioperative and postoperative surgical complications for elderly and younger patients, underlining the safety of the surgical approach itself in the older patient population.

Our findings may have some clinical impact. Since the natural course of untreated PEH is estimated to be 


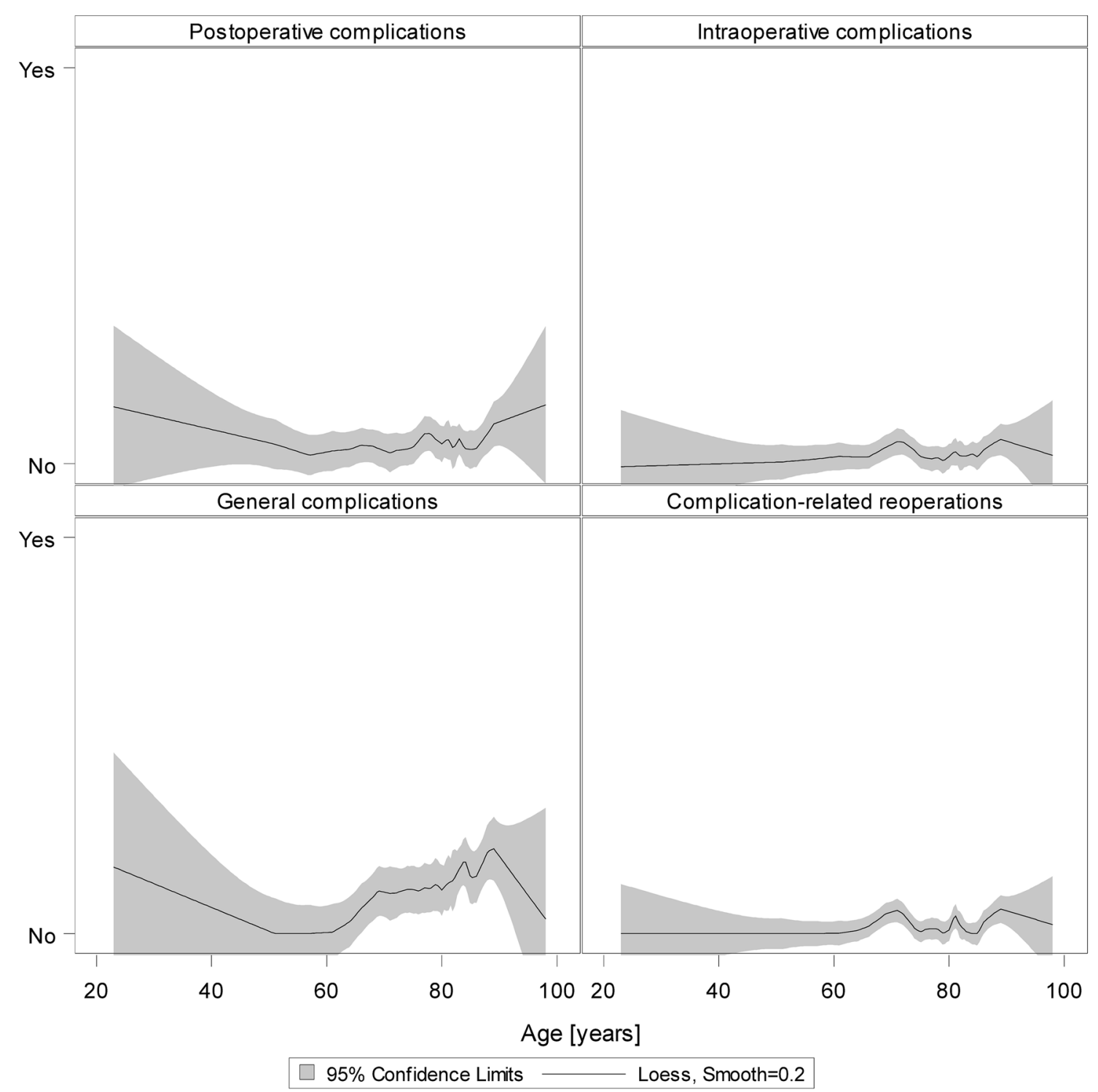

Fig. 5 Loess regression for postoperative, intraoperative and general complications as well as complication-related reoperations for patients of the matched sample $($ smooth $=0.2)$

associated with an annual symptom progression in $14 \%$ of patients, requiring emergency surgery in $1.1 \%$ of cases $[17,18]$, elective surgery seems important, especially for elderly patients. Our data support the concept of elective PEH repair in elderly patients with a low surgical mortality and morbidity. The surgical approach in elderly patients with PEH seems appropriate to significantly improve the quality of life [3] and prevent higher mortality and morbidity rates in emergency settings $[6,19,20]$. However, the higher rate of postoperative pneumonia in the older patient population underlines the importance of careful perioperative management and preventive strategies for general complications. Perioperative physiotherapy and respiratory training may help to reduce the risk of pulmonary complications after surgery [21].

Since this is a registry-based study, there are some limitations. Data on preventive respiratory strategies such as breathing exercises or inhalations are not recorded in the Herniamed Registry. Therefore, the potential effect of preventive respiratory physiotherapy in our patient population remains unknown. However, the following measurements are used to optimize data entry in the Herniamed Registry: signed contract with the responsible surgeon for data correctness and completeness, indication of missing data by the software, once again review of the perioperative outcome at 1-year follow-up and control of the data entry by experts as 
part of the certification process of hernia centers. Furthermore, to overcome the confounding bias of analyzing two different patient populations, a propensity score (PS) was applied in our study [22].

In summary, our study shows that age $\geq 80$ years in itself is not a risk factor for higher intraoperative or postoperative complication rates compared to younger patients in elective PEH repair. However, careful perioperative management with prevention of respiratory complications seems of utmost importance in elderly patients. Further studies investigating recurrence rates and long-term complications are needed to evaluate the effectiveness of elective PEH repair in octogenarians and nonagenarians.

\section{Compliance with ethical standards}

Disclosures F Köckerling — grants to fund the Herniamed Registry from Johnson \& Johnson, Norderstedt; pfm medical, Cologne; Dahlhausen, Cologne; B Braun, Tuttlingen; MenkeMed, Munich and Bard, Karlsruhe. D Adolf-fees for statistical support from Herniamed gGmbH, Berlin. RF Staerkle, I Rosenblum, H Hoffmann, FS Lehmann, R Bittner, P Kirchhoff, and PM Glauser have no conflicts of interest or financial ties to disclose.

OpenAccess This article is distributed under the terms of the Creative Commons Attribution 4.0 International License (http://creativeco mmons.org/licenses/by/4.0/), which permits unrestricted use, distribution, and reproduction in any medium, provided you give appropriate credit to the original author(s) and the source, provide a link to the Creative Commons license, and indicate if changes were made.

\section{References}

1. Kahrilas PJ, Kim HC, Pandolfino JE (2008) Approaches to the diagnosis and grading of hiatal hernia. Best Pract Res Clin Gastroenterol 22(4):601-616. https://doi.org/10.1016/j.bpg.2007.12.007

2. Lal DR, Pellegrini CA, Oelschlager BK (2005) Laparoscopic repair of paraesophageal hernia. Surg Clin North Am 85(1):105118. https://doi.org/10.1016/j.suc.2004.09.008.x.

3. Hazebroek EJ, Gananadha S, Koak Y, Berry H, Leibman S, Smith GS (2008) Laparoscopic paraesophageal hernia repair: quality of life outcomes in the elderly. Dis Esophagus 21(8):737-741. https ://doi.org/10.1111/j.1442-2050.2008.00831.x

4. Allen MS, Trastek VF, Deschamps C, Pairolero PC (1993) Intrathoracic stomach. Presentation and results of operation. J Thorac Cardiovasc Surg 105(2):253-258 (discussion 258-259)

5. Hallissey MT, Ratliff DA, Temple JG (1992) Paraoesophageal hiatus hernia: surgery for all ages. Ann R Coll Surg Engl 74(1):23-25

6. Poulose BK, Gosen C, Marks JM, Khaitan L, Rosen MJ, Onders RP, Trunzo JA, Ponsky JL (2008) Inpatient mortality analysis of paraesophageal hernia repair in octogenarians. J Gastrointest Surg 12(11):1888-1892. https://doi.org/10.1007/s11605-008-0625-5

7. Gangopadhyay N, Perrone JM, Soper NJ, Matthews BD, Eagon JC, Klingensmith ME, Frisella MM, Brunt LM (2006) Outcomes of laparoscopic paraesophageal hernia repair in elderly and highrisk patients. Surgery 140(4):491-498. https://doi.org/10.1016/j. surg.2006.07.001 (discussion 498-499).

8. Louie BE, Blitz M, Farivar AS, Orlina J, Aye RW (2011) Repair of symptomatic giant paraesophageal hernias in elderly $(>70$ years) patients results in improved quality of life. J Gastrointest Surg 15(3):389-396. https://doi.org/10.1007/s11605-010-1324-6

9. Merzlikin OV, Louie BE, Farivar AS, Shultz D, Aye RW (2017) Repair of symptomatic paraesophageal hernias in elderly ( $>70$ years) patients results in sustained quality of life at 5 years and beyond. Surg Endosc 31(10):3979-3984. https://doi.org/10.1007/ s00464-017-5432-1

10. Parker DM, Rambhajan AA, Horsley RD, Johanson K, Gabrielsen JD, Petrick AT (2017) Laparoscopic paraesophageal hernia repair is safe in elderly patients. Surg Endosc 31(3):1186-1191. https:// doi.org/10.1007/s00464-016-5089-1

11. Spaniolas K, Laycock WS, Adrales GL, Trus TL (2014) Laparoscopic paraesophageal hernia repair: advanced age is associated with minor but not major morbidity or mortality. J Am Coll Surg 218(6):1187-1192. https://doi.org/10.1016/j.jamcollsur g.2013.12.058

12. Latzko M, Borao F, Squillaro A, Mansson J, Barker W, Baker T (2014) Laparoscopic repair of paraesophageal hernias. JSLS. https ://doi.org/10.4293/JSLS.2014.00009

13. Stechemesser B, Jacob DA, Schug-Pass C, Kockerling F (2012) Herniamed: an internet-based registry for outcome research in hernia surgery. Hernia 16(3):269-276. https://doi.org/10.1007/ s10029-012-0908-3

14. Köckerling F, Bittner R, Kofler M, Mayer F, Adolf D, Kuthe A, Weyhe D (2017) Lichtenstein versus total extraperitoneal patch plasty versus transabdominal patch plasty technique for primary unilateral inguinal hernia repair: a registry-based, propensity score-matched comparison of 57,906 patients. Ann Surg. https:// doi.org/10.1097/SLA.0000000000002541

15. Mennigen R, Senninger N (2015) Is there an age limit for surgical interventions?. Zentralbl Chir 140(3):304-311. https://doi. org/10.1055/s-0032-1328214

16. Higashi S, Nakajima K, Tanaka K, Miyazaki Y, Makino T, Takahashi T, Kurokawa Y, Yamasaki M, Takiguchi S, Mori M, Doki Y (2017) Laparoscopic anterior gastropexy for type III/IV hiatal hernia in elderly patients. Surg Case Rep 3(1):45. https://doi. org/10.1186/s40792-017-0323-1

17. Stylopoulos N, Gazelle GS, Rattner DW (2002) Paraesophageal hernias: operation or observation? Ann Surg 236(4):492-500. https://doi.org/10.1097/01.SLA.0000029000.06861.17 (discussion 500-491).

18. Treacy PJ, Jamieson GG (1987) An approach to the management of para-oesophageal hiatus hernias. Aust N Z J Surg 57(11):813-817

19. Staerkle RF, Skipworth RJ, Hansen RD, Hazebroek EJ, Smith GS, Leibman S (2015) Acute paraesophageal hernia repair: short-term outcome comparisons with elective repair. Surg Laparosc Endosc Percutan Tech 25(2):147-150. https://doi.org/10.1097/SLE.00000 00000000098

20. Tam V, Luketich JD, Winger DG, Sarkaria IS, Levy RM, Christie NA, Awais O, Shende MR, Nason KS (2017) Non-elective paraesophageal hernia repair portends worse outcomes in comparable patients: a propensity-adjusted analysis. J Gastrointest Surg 21(1):137-145. https://doi.org/10.1007/s11605-016-3231-y

21. Boden I, Skinner EH, Browning L, Reeve J, Anderson L, Hill C, Robertson IK, Story D, Denehy L (2018) Preoperative physiotherapy for the prevention of respiratory complications after upper abdominal surgery: pragmatic, double blinded, multicentre randomised controlled trial. BMJ 360:j5916. https://doi.org/10.1136/ bmj.j5916

22. Lonjon G, Porcher R, Ergina P, Fouet M, Boutron I (2017) Potential pitfalls of reporting and bias in observational studies with propensity score analysis assessing a surgical procedure: a methodological systematic review. Ann Surg 265(5):901-909. https:// doi.org/10.1097/SLA.0000000000001797 